\title{
Solvent controlled selective photocatalytic oxidation of benzyl alcohol over $\mathrm{Ni} @ \mathrm{C} / \mathrm{TiO}_{2}$
}

Zhenlong Song ${ }^{\mathrm{a}, \mathrm{c}}$, Jianguo Liu ${ }^{\mathrm{b} *}$, Qi Zhang ${ }^{\mathrm{b} *}$

${ }^{a}$ Department of Engineering Science, University of Science and Technology of China, Hefei 230026, P.R. China.

${ }^{\mathrm{b}}$ Key Laboratory of Energy Thermal Conversion and Control of Ministry of Education, School of Energy and Environment, Southeast University, Nanjing 210096, PR China.

${ }^{c}$ Guangzhou Institute of Energy Conversion, Chinese Academy of Sciences, Guangzhou 510640, PR China.

*Corresponding author: liujg@seu.edu.cn; zhangqiseu@ seu.edu.cn

\begin{abstract}
The oxidation of aromatic alcohols to produce carbonyl compounds is of great significance in fine chemical production. The traditional oxidation produces waste gas and pollutes the environment during the reaction. As a new field, photocatalysis has attracted people's attention because of its environmental friendliness. At present, there have been much research on $\mathrm{TiO}_{2}$, or noble metal modified $\mathrm{TiO}_{2}$ to catalyze alcohol oxidation, but the high cost is not conducive to large-scale production. Herein, a $\mathrm{Ni} @ \mathrm{C} / \mathrm{TiO}_{2}$ catalyst was prepared by in-situ hydrothermal synthesis. This catalyst has a better oxidation effect on benzyl alcohol than $\mathrm{Ni} @ \mathrm{C}$ supported on $\mathrm{TiO}_{2}$ on the market and has a good catalytic effect on aromatic alcohols with different substituents. It is more interesting that the selectivity of the product can be adjusted by choosing different reaction solvents. The highly active catalyst with low cost and wide applicability has certain significance for the large-scale use of photocatalytic alcohol oxidation.
\end{abstract}

Keywords: photocatalysis, alcohol oxidation, solvent controlled, titanium oxide.

\section{Introduction}

As important chemical products, benzaldehyde or benzoic acid is widely used in perfumes, dyes, and pharmaceutical intermediates ${ }^{[1]}$. At present, the preparation methods of benzaldehyde mainly include the oxidation of benzyl alcohol, the oxidation of toluene, and the hydrolysis of benzyl chloride ${ }^{[2]}$. Among them, benzyl alcohol oxidation is widely used because of its low cost. Commonly used oxidants or catalysts for the oxidation of benzyl alcohol include chromic acid, dichromate, permanganate, and precious metal catalysts ${ }^{[3-6]}$. However, these oxidation methods 
have some disadvantages. For example, the waste generated from the used oxidant would pollute the environment and is prone to excessive oxidation. So, it is very important and necessary to find a green oxidant.<smiles>Nc1cccc2c1CN(C1CCC(=O)NC1=O)C2=O</smiles>

Revlimid<smiles>O=C(O)c1ccc2nc(-c3cc(Cl)cc(Cl)c3)oc2c1</smiles>

Vyndamax<smiles>CC(O)=C(C#N)C(=O)Nc1ccc(C(F)(F)F)cc1</smiles>

Aubagio<smiles>COC(=O)C(c1ccccc1)C1CCCCN1</smiles>

Concerta<smiles>CC(=O)Oc1ccccc1C(=O)O</smiles>

Aspirin Cardio<smiles>Nc1ccc(O)c(C(=O)O)c1</smiles>

Canasa

Figure 1 Carbonyl-containing pharmaceutical intermediates

As a green and cheap oxidant, $\mathrm{O}_{2}$ can be used to replace traditional $\mathrm{KMnO}_{4}$ or tert-butyl hydroperoxide, which helps reduce reaction costs and reduce pollutant emissions $^{[7]}$. To promote the oxidation of benzyl alcohol, a series of nanoparticle catalysts have been prepared, such as $\mathrm{Au}, \mathrm{Ru}, \mathrm{Pd}$, and other nanoparticles ${ }^{[8]}$. Among them, Pd-based catalysts have a strong ability to activate oxygen and can generate aldehydes with high selectivity, so they are widely used ${ }^{[9-11]}$. The catalytic activity of precious metal nanoparticle catalysts is greatly affected by size and valence $^{[12]}$. Therefore, to control the reaction selectivity and improve the catalytic ability of the catalyst, people try to dope the catalyst with other metals ${ }^{[13]}$. Au/Pd$\mathrm{TiO}_{2}$ catalysts can efficiently oxidize primary alcohols to produce aldehydes under solvent-free conditions, in which Au doping influences the structure and electrons of Pd nanoparticles ${ }^{[14]}$. While the precious metal catalyst is difficult to use on a large scale due to its high cost. Therefore, the development of an environmentally friendly and cheap benzyl alcohol oxidation method is of great significance for the industrial preparation of benzaldehyde and benzoic acid.

Since Fujishima et al. ${ }^{[15]}$ discovered that $\mathrm{TiO}_{2}$ can photolyze water to hydrogen under UV irradiation, the field of photocatalysis has attracted much attention. Photocatalysis is a process of converting light energy into chemical energy. Under the excitation of photons, electrons transition from the valence band to the conduction 
band and generate holes, thereby generating active free radicals-hydroxyl radicals to promote the oxidation of the substrate ${ }^{[16,17]}$. At present, photocatalytic technology has been widely used in the fields of photolysis of water to produce hydrogen, alcohol oxidation, and oxidative degradation of organic waste ${ }^{[18-20]}$. Common photocatalysts include $\mathrm{ZnO}^{[21,22]}, \mathrm{SnO}^{[23,24]}, \mathrm{CdS}^{[25-27]}, \mathrm{TiO}_{2}{ }^{[28-32]}$, etc. Among them, $\mathrm{TiO}_{2}$ is favored because of its low price, stable properties, and non-toxicity. The bandgap energy of $\mathrm{TiO}_{2}$ is $3.2 \mathrm{eV}$, which inhibits its absorption of visible light. In addition, the electrons, and holes of $\mathrm{TiO}_{2}$ recombine quickly, which also leads to a lower quantum yield ${ }^{[33]}$. The Carbon $\operatorname{dot} / \mathrm{TiO}_{2}$ catalyst ${ }^{[34]}$ overcomes the problem of the short excited state lifetime of carbon quantum dots and has a good catalytic effect under the irradiation of blue or green light. $\mathrm{Lu} \mathrm{Xu}^{[35]}$ modified carbon quantum dots on $\mathrm{N}$-doped $\mathrm{TiO}_{2}$ and prepared $\mathrm{C}-\mathrm{N}-\mathrm{TiO}_{2}-\mathrm{x}$ composite material, and found that this material has stronger visible light absorption capacity and higher charge separation efficiency than $\mathrm{TiO}_{2}$ without $\mathrm{N}$ or carbon quantum dots. In addition, adding an appropriate amount of citric acid to remove holes can significantly increase the reduction rate of $\mathrm{Cr}$ (VI). More research on metal-modified $\mathrm{TiO}_{2}$, such as $\mathrm{Pd} / \mathrm{TiO}_{2}{ }^{[36,}{ }^{37]}, \mathrm{Au} / \mathrm{TiO}_{2}{ }^{[38]}, \mathrm{Pt} / \mathrm{TiO}_{2}{ }^{[39,40]}$ showed their great significance photocatalytic oxidation of aromatic alcohols.

In this study, $\mathrm{Ni@C}$ was loaded on self-made $\mathrm{TiO}_{2}$ by in-situ hydrothermal synthesis, which has a better photocatalytic effect on the oxidation of benzyl alcohol than the by commercial $\mathrm{TiO}_{2}$ supported by $\mathrm{Ni} @ \mathrm{C}$. In addition, aromatic alcohols with different substituents are used as reaction substrates, and good conversion rate and selectivity are also obtained, which shows that the catalyst has a wide range of applicability. What is interesting is that the catalytic effect of the catalyst is significantly different in different solvents. By controlling the reaction solvent, the production of aldehydes or acids can be regulated. This is conducive to the application of the catalyst in actual production.

\section{Experimental section}

\subsection{Catalyst preparation}

$\mathrm{Ni} @ \mathrm{C}$ was prepared according to the method of Liu ${ }^{[41]}$. Weigh $0.03 \mathrm{~mol}$ of $\mathrm{Ni}$ $\left(\mathrm{NO}_{3}\right) \cdot 6 \mathrm{H}_{2} \mathrm{O}$ and citric acid and dissolve them in $20 \mathrm{ml}$ of absolute ethanol. The mixture was stirred at $70{ }^{\circ} \mathrm{C}$ for $8 \mathrm{~h}$ and dried at $100{ }^{\circ} \mathrm{C}$ for $48 \mathrm{~h}$ after stirring. The dried green solid was ground into a powder and calcined in an $\mathrm{N}_{2}$ atmosphere for $3 \mathrm{~h}$, the calcining temperature was $700{ }^{\circ} \mathrm{C}$. The black solid obtained after calcination was 
washed with1 $1 \mathrm{M} \mathrm{H}_{2} \mathrm{SO}_{4}$ until it was colorless, and then washed with deionized water until the $\mathrm{pH}$ of the waste liquid was 7 , and then the solid was freeze-dried at $-48{ }^{\circ} \mathrm{C}$ for 12 h to obtain $\mathrm{Ni@C.}$

Place $10 \mathrm{ml}$ of tetrabutyl titanate and $10 \mathrm{ml}$ of ethanol in the lining of a $100 \mathrm{ml}$ polytetrafluororeactor, stir for 5 minutes, add $150 \mathrm{mg}$ of $\mathrm{Ni} @ \mathrm{C}$ and $3 \mathrm{ml}$ of deionized water, and magnetically stir at room temperature for 3 hours. After that, the autoclave reactor (Anhui Kemi Machinery Technology Co., Ltd, Anhui, China) was heated at $150^{\circ} \mathrm{C}$ for 12 hours. When it was cooled to room temperature washed and filtered. Then put the filtered solid into an oven at $100^{\circ} \mathrm{C}$, and evaporate and dry to obtain the $\mathrm{Ni} @ \mathrm{C} / \mathrm{TiO}_{2}-\mathrm{Z}$.

Weigh $120 \mathrm{mg}$ of commercially available $\mathrm{TiO}_{2}$ and $120 \mathrm{mg}$ of $\mathrm{Ni} @ \mathrm{C}$ into $80 \mathrm{ml}$ of ultrapure water, stir at room temperature for $24 \mathrm{~h}$ under shading. After centrifugation and washing with ultrapure water, the obtained solid is freeze-dried to obtain $\mathrm{Ni} @ \mathrm{C}-\mathrm{TiO}_{2}$. The commercially available $\mathrm{TiO}_{2}$ used is all anatase $\mathrm{TiO}_{2}$ from Macklin, and the prepared catalyst is named according to the particle size of the $\mathrm{TiO}_{2}$.

They are $\mathrm{Ni} @ \mathrm{C} / \mathrm{TiO}_{2}-5 \mathrm{~nm}, \mathrm{Ni} @ \mathrm{C} / \mathrm{TiO}_{2}-5 \sim 10 \mathrm{~nm}, \mathrm{Ni} @ \mathrm{C} / \mathrm{TiO}_{2}-10 \sim 25 \mathrm{~nm}$, $\mathrm{Ni} @ \mathrm{C} / \mathrm{TiO}_{2}-40 \mathrm{~nm}, \mathrm{Ni} @ \mathrm{C} / \mathrm{TiO}_{2}-100 \mathrm{~nm}, \mathrm{Ni} @ \mathrm{C} / \mathrm{TiO}_{2}-150$ nm.

\subsection{Product quantification}

The composition of reaction filtrate was performed onthe GC-2014C (Shimadzu, Japan) with the SH-Stabilwax-DA capillary column $(30 \mathrm{~m} \times 0.25 \mathrm{~mm} \times 0.25 \mu \mathrm{m})$ and FID detector.

\section{Results and discussion}

\subsection{Screening catalyst}

To test the photocatalytic oxidation of benzyl alcohol, various $\mathrm{Ni} @ \mathrm{C} / \mathrm{TiO}_{2}$ have been used in the oxidation of benzyl alcohol, and results are shown in Table 1. It can be seen that the $\mathrm{Ni} @ \mathrm{C} / \mathrm{TiO}_{2}$ shows the good performance in producing benzaldehyde with a selectivity up to $100 \%$. The conversion over the commercially available $\mathrm{TiO}_{2}$ supported Ni@C gradually decreases with the increase of the $\mathrm{TiO}_{2}$ particle size. Because the smaller the catalyst particle size, the larger the specific surface area, which promotes the contact between the substrate and oxygen and the catalyst. The radiation under $450 \mathrm{~nm}$ and $520 \mathrm{~nm}$ wavelengths were used in the reaction. The shorter the wavelength taken, the greater the energy input. Therefore, the conversion rate of the same catalyst under the radiation of $450 \mathrm{~nm}$ wavelength is higher than that 
of $520 \mathrm{~nm}$ (Table 1, entry 2-13). It is interesting that under the same conditions, selfmade $\mathrm{TiO}_{2}$ supported $\mathrm{Ni} @ \mathrm{C}$ catalyst is better than $\mathrm{Ni} @ \mathrm{C} / \mathrm{TiO}_{2}-5 \mathrm{~nm}$, which is the commercially available $\mathrm{TiO}_{2}$ supported Ni@C. Table 1 Different catalysts catalyzed the oxidation of benzyl alcohol to benzaldehyde

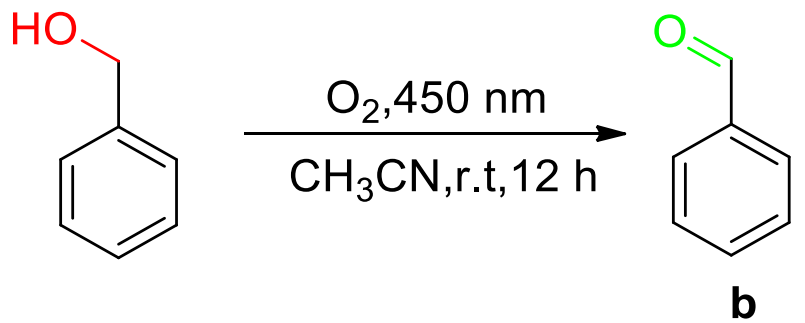

\begin{tabular}{|c|c|c|c|c|c|}
\hline Entry & Catalyst & $\lambda$ & Solvent & Con. $(\%)$ & Sel. $^{\mathrm{b}}(\%)$ \\
\hline 1 & $\mathrm{Ni@C/TiO}-\mathrm{Z}$ & 450 & $\mathrm{CH}_{3} \mathrm{CN}$ & 34.86 & 100.00 \\
\hline 2 & $\mathrm{Ni} @ \mathrm{C} / \mathrm{TiO}_{2}-5$ nm & 450 & $\mathrm{CH}_{3} \mathrm{CN}$ & 27.59 & 100.00 \\
\hline 3 & 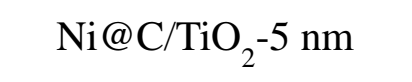 & 520 & $\mathrm{CH}_{3} \mathrm{CN}$ & 1.94 & 100.00 \\
\hline 4 & $\mathrm{Ni} @ \mathrm{C} / \mathrm{TiO}_{2}-5 \sim 10 \mathrm{~nm}$ & 450 & $\mathrm{CH}_{3} \mathrm{CN}$ & 18.60 & 100.00 \\
\hline 5 & $\mathrm{Ni} @ \mathrm{C} / \mathrm{TiO}_{2}-5 \sim 10 \mathrm{~nm}$ & 520 & $\mathrm{CH}_{3} \mathrm{CN}$ & 5.48 & 100.00 \\
\hline 6 & $\mathrm{Ni} @ \mathrm{C} / \mathrm{TiO}_{2}-10 \sim 25 \mathrm{~nm}$ & 450 & $\mathrm{CH}_{3} \mathrm{CN}$ & 8.39 & 100.00 \\
\hline 7 & $\mathrm{Ni} @ \mathrm{C} / \mathrm{TiO}_{2}-10 \sim 25 \mathrm{~nm}$ & 520 & $\mathrm{CH}_{3} \mathrm{CN}$ & 1.90 & 100.00 \\
\hline 8 & $\mathrm{Ni@C/TiO}-40$ nm & 450 & $\mathrm{CH}_{3} \mathrm{CN}$ & 7.50 & 100.00 \\
\hline 9 & $\mathrm{Ni} @ \mathrm{C} / \mathrm{TiO}_{2}-40$ nm & 520 & $\mathrm{CH}_{3} \mathrm{CN}$ & 0.65 & 100.00 \\
\hline 10 & $\mathrm{Ni} @ \mathrm{C} / \mathrm{TiO}_{2}-100 \mathrm{~nm}$ & 450 & $\mathrm{CH}_{3} \mathrm{CN}$ & 14.90 & 100.00 \\
\hline 11 & $\mathrm{Ni@C/TiO}-100$ nm & 520 & $\mathrm{CH}_{3} \mathrm{CN}$ & 1.56 & 100.00 \\
\hline 12 & $\mathrm{Ni} @ \mathrm{C} / \mathrm{TiO}_{2}-150 \mathrm{~nm}$ & 450 & $\mathrm{CH}_{3} \mathrm{CN}$ & 0.48 & 100.00 \\
\hline 13 & $\mathrm{Ni} @ \mathrm{C} / \mathrm{TiO}_{2}-150 \mathrm{~nm}$ & 520 & $\mathrm{CH}_{3} \mathrm{CN}$ & 0.26 & 100.00 \\
\hline
\end{tabular}

${ }^{\text {a }}$ Reaction conditions: $0.2 \mathrm{mmol}$ benzyl alcohol, $20 \mathrm{mg}$ catalyst, r.t. ${ }^{\mathrm{b}}$ the conversion and selectivity are determined by GC analysis.

3.2 Optimization of reaction conditions 
Based on the above results, $\mathrm{Ni} @ \mathrm{C} / \mathrm{TiO}_{2}-5 \mathrm{~nm}$ and $\mathrm{Ni} @ \mathrm{C} / \mathrm{TiO}_{2}-\mathrm{Z}$ were taken to catalyze benzyl alcohol oxidization at different wavelengths and in different reaction time. The results are shown in Figure 1. As the wavelength decreasing, the conversion of benzyl alcohol gradually increases, but when the wavelength is reduced to $365 \mathrm{~nm}$, the selectivity of benzaldehyde is significantly reduced. The greater the energy from the radiation of the shorter wavelength leads to further oxidation of benzaldehyde to benzoic acid.
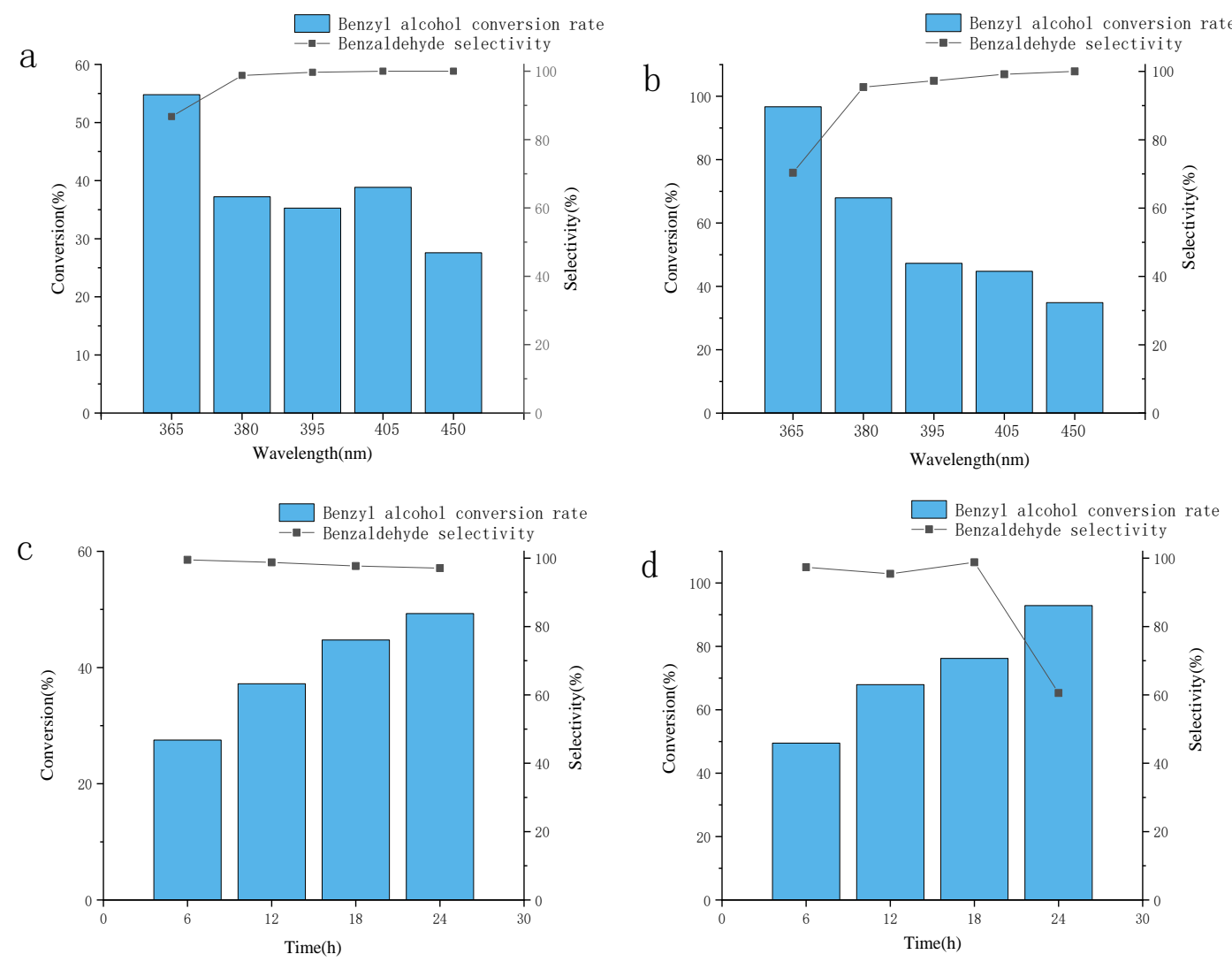

Figure 2 Optimization of conditions for oxidation of benzyl alcohol (a: $\mathrm{Ni} @ \mathrm{C} / \mathrm{TiO}_{2}-5$ nm at different wavelengths; b: $\mathrm{Ni} @ \mathrm{C} / \mathrm{TiO}_{2}-\mathrm{Z}$ at different wavelengths; c:

$\mathrm{Ni} @ \mathrm{C} / \mathrm{TiO}_{2}-5 \mathrm{~nm}$ at different reaction times; $\mathrm{d}$ : $\mathrm{Ni} @ \mathrm{C} / \mathrm{TiO}_{2}-\mathrm{Z}$ at different reaction times)

Considering that benzaldehyde oxidized to benzoic acid at $365 \mathrm{~nm}$ wavelength, the subsequent choice of $380 \mathrm{~nm}$ wavelength is to investigate the effect of reaction time on product yield and selectivity. The conversion of benzyl alcohol increased with the increase of the reaction time. When the $\mathrm{Ni} @ \mathrm{C} / \mathrm{TiO}_{2}-\mathrm{Z}$ was used, the conversion rate of benzyl alcohol was $49.48 \%$ after $6 \mathrm{~h}$, and the conversion rate of benzyl alcohol increased to $92.88 \%$ after $24 \mathrm{~h}$ of reaction (Figure $2 \mathrm{c}$ and d). In general, the activity of $\mathrm{Ni} @ \mathrm{C} / \mathrm{TiO}_{2}-\mathrm{Z}$ is better than that of $\mathrm{Ni} @ \mathrm{C} / \mathrm{TiO}_{2}-5 \mathrm{~nm}$ under the same reaction 
conditions. To obtain a high conversion of benzyl alcohol while preventing excessive oxidation of benzaldehyde, $\mathrm{Ni} @ \mathrm{C} / \mathrm{TiO} 2-\mathrm{Z}$ is selected as the catalyst, and a reaction at a wavelength of $380 \mathrm{~nm}$ for $18 \mathrm{~h}$ is a suitable condition.

\subsection{Solvent screening and catalyst recycling performance}

Table 2 Photocatalytic oxidation of benzyl alcohol in different solvents

\begin{tabular}{ccccccc} 
& & & & \\
\hline
\end{tabular}

${ }^{\text {a Reaction conditions: } 0.2 \mathrm{mmol} \text { benzyl alcohol, } 20 \mathrm{mg} \text { catalyst, r.t. }{ }^{\text {b,c }} \text { The conversion }}$ and selectivity are determined by GC analysis.

Different solvents were then tested in photocatalytic oxidation of benzyl alcohol. When ethanol, 1,4-dioxane and water are used as the reaction solvent, the conversion rate of benzyl alcohol is low. When acetonitrile is selected as the reaction solvent, the conversion of benzyl alcohol is higher, and the selectivity of benzaldehyde reaches 98.79\%. When dichloromethane, acetone, ethyl acetate and 1,2-dichloroethane are selected as the reaction solvent, a higher conversion rate of benzyl alcohol is also obtained, but the product is mainly benzoic acid. Ethanol and ethyl acetate have the 
same polarity, but the conversion rate of benzyl alcohol and product selectivity are quite different. It seems that the polarity of the solvent has little effect on the reaction, and the solvent's ability to dissolve oxygen is the main factor affecting the reaction effect. From the perspective of environmental protection, acetonitrile and ethyl acetate are selected as the reaction solvent from the above solvents to generate benzaldehyde and benzoic acid, respectively.

Table 3 The effect of different volume ratios of acetonitrile and ethyl acetate on

\begin{tabular}{|c|c|c|c|c|c|}
\hline Entry & $\mathrm{CH}_{3} \mathrm{CN}$ : & Ethyl Acetate & Con. $(\%)$ & Sel. $^{\mathrm{b}}(\%)$ & $\operatorname{Sel}^{\mathrm{c}}(\%)$ \\
\hline 1 & & $1: 0$ & 76.22 & 98.79 & 1.21 \\
\hline 2 & & $10: 1$ & 75.39 & 83.18 & 16.82 \\
\hline 3 & & $1: 1$ & 75.86 & 75.10 & 24.90 \\
\hline 4 & & $1: 10$ & 80.98 & 56.22 & 43.78 \\
\hline 5 & & $0: 1$ & 98.84 & 2.24 & 97.76 \\
\hline
\end{tabular}

${ }^{\text {a Reaction conditions: } 0.2 \mathrm{mmol} \text { benzyl alcohol, } 20 \mathrm{mg} \text { catalyst, r.t. }{ }^{\text {b,c }} \text { The conversion }}$ and selectivity are determined by GC analysis.

To further study the influence of the solvent on the product selectivity, acetonitrile and ethyl acetate with different volume ratios were selected as the reaction solvents under the premise of keeping the volume of the reaction solvent unchanged (Table 3). The results showed that as the volume of ethyl acetate increased, the conversion of the continued to increase, the selectivity of benzaldehyde decreased and the selectivity of benzoic acid increased, which indicated that the presence of ethyl acetate could make the reaction system more oxidative. 

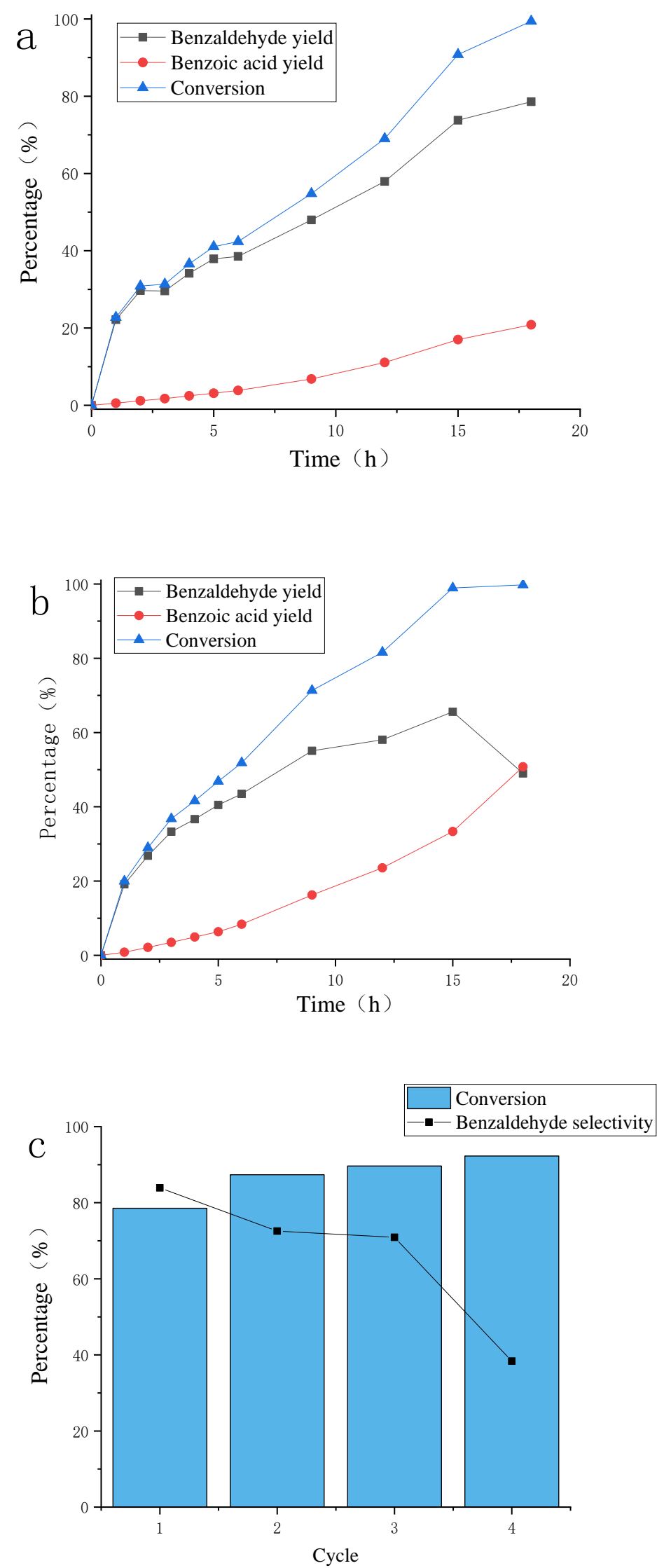

Figure 3. Product yield at different stages of the reaction and reusability of 
$\mathrm{Ni} @ \mathrm{C} / \mathrm{TiO}_{2}-\mathrm{Z}$. a: Product yield at different stages of the reaction in $\mathrm{CH}_{3} \mathrm{CN}-\mathrm{D} 3$; b: Product yield at different stages of the reaction in Acetone-D8; c: Reusability of $\mathrm{Ni} @ \mathrm{C} / \mathrm{TiO}_{2}-\mathrm{Z}$

Monitoring the changes of products and substrates at each stage of the reaction process is of great significance to the study of the reaction mechanism. Therefore, deuterated reagents are used to replace conventional reagents, samples are continuously taken out, and tested by NMR to study the changes of various substances. Choose $\mathrm{CH}_{3} \mathrm{CN}$-D3 and acetone-D8 as reaction solvents (Due to the high price of ethyl acetate-D8, Acetone-D8 which has the same effect as it is chosen). Studies have shown that benzoic acid is formed at the beginning of the reaction. In the two solvents, benzaldehyde is mainly generated in the early stage of the reaction. When the benzyl alcohol is exhausted, the benzaldehyde in acetone-D8 continues to be oxidized to generate benzoic acid (Figure $\mathbf{3}$ a and $\mathrm{b}$ ) .

The stability and recycling capacity of the catalyst is a key index to evaluate the performance of the catalyst. So, $\mathrm{Ni} @ \mathrm{C} / \mathrm{TiO}_{2}-\mathrm{Z}$ recycling experiment was carried out. After reacting in acetonitrile solvent at $380 \mathrm{~nm}$ wavelength for $18 \mathrm{~h}$, the conversion of benzyl alcohol did not decrease after 4 cycles (Figure 3 c).

\subsection{Substrate expansion}

Table 4 The substrate scope of alcohols in $\mathrm{CH}_{3} \mathrm{CN}$ 


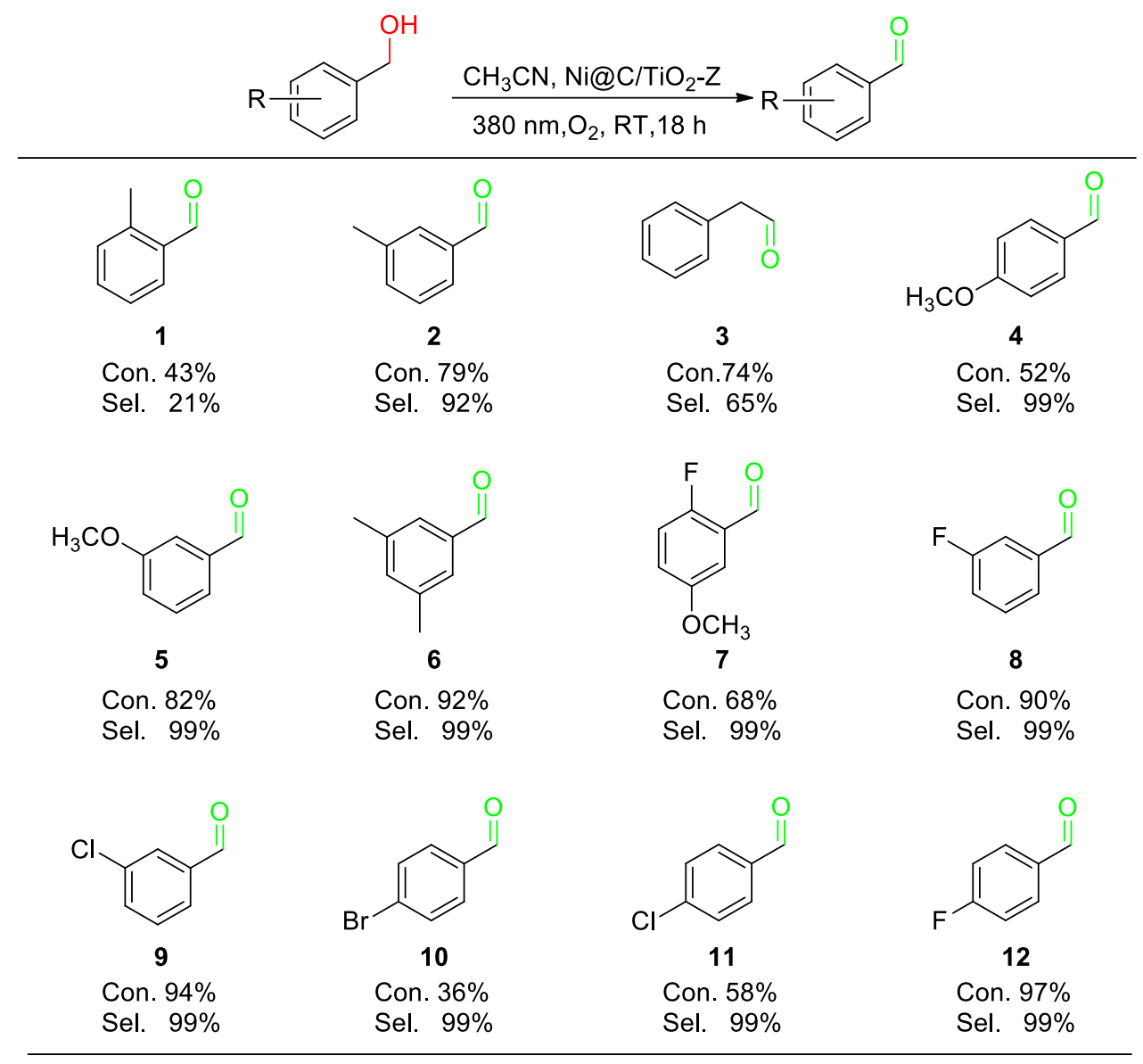

Reaction conditions: $0.2 \mathrm{mmol}$ benzyl alcohol, $20 \mathrm{mg}$ catalyst, r.t. The conversion and selectivity are determined by GC analysis.

Acetonitrile and ethyl acetate were selected as the reaction solvents, and $\mathrm{Ni} @ \mathrm{C} / \mathrm{TiO}_{2}-\mathrm{Z}$ was used to catalyze aromatic alcohols with different substituents (Table 4 and 5). The results show that $\mathrm{Ni} @ \mathrm{C} / \mathrm{TiO}_{2}-\mathrm{Z}$ also has a general catalytic effect on other substrates, and acetonitrile solvent still tends to generate aldehydes, while ethyl acetate solvent tends to generate acids.

Table 5 The substrate scope of alcohols in ethyl acetate 


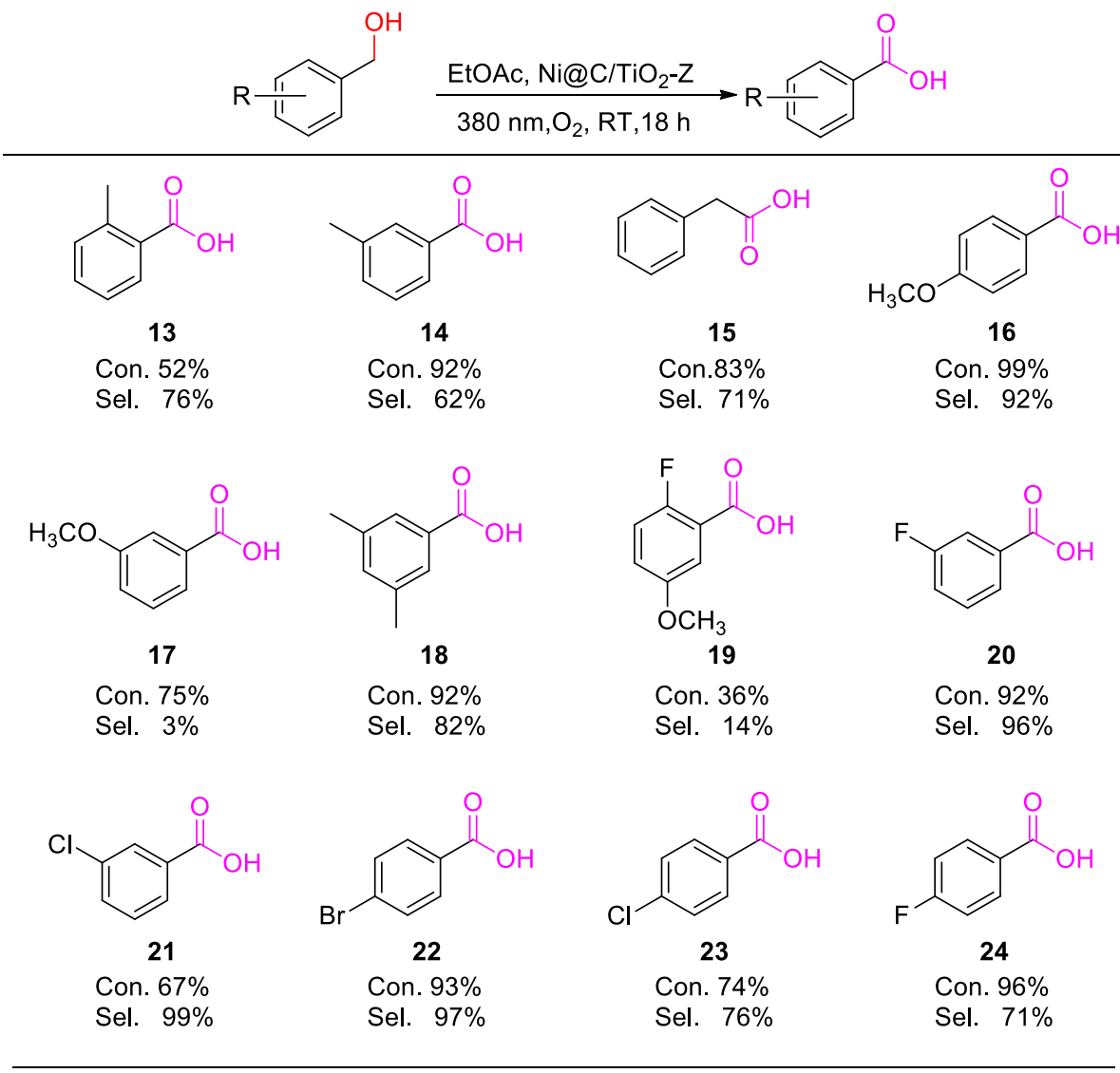

Reaction conditions: $0.2 \mathrm{mmol}$ benzyl alcohol, $20 \mathrm{mg}$ catalyst, r.t. The conversion and selectivity are determined by GC analysis.

The presence of electron withdrawing groups is beneficial to the oxidation of the substrate, and this promoting ability is consistent with the electron withdrawing ability ( $\mathrm{F}->\mathrm{Cl}->\mathrm{Br}->\mathrm{MeO}-)$. And the electron withdrawing effect in the para position is stronger than that in the meta position. While the existence of the electron-donating group at the ortho position inhibits the oxidation reaction of the substrate, which has almost no effect at the meta position. When there is a methyl group at the meta position, the oxidation reaction of the substrate is not inhibited. This shows that the steric hindrance effect is stronger than Me- (Table 4, 2 and 6) .

\subsection{Catalyst's physicochemical properties}



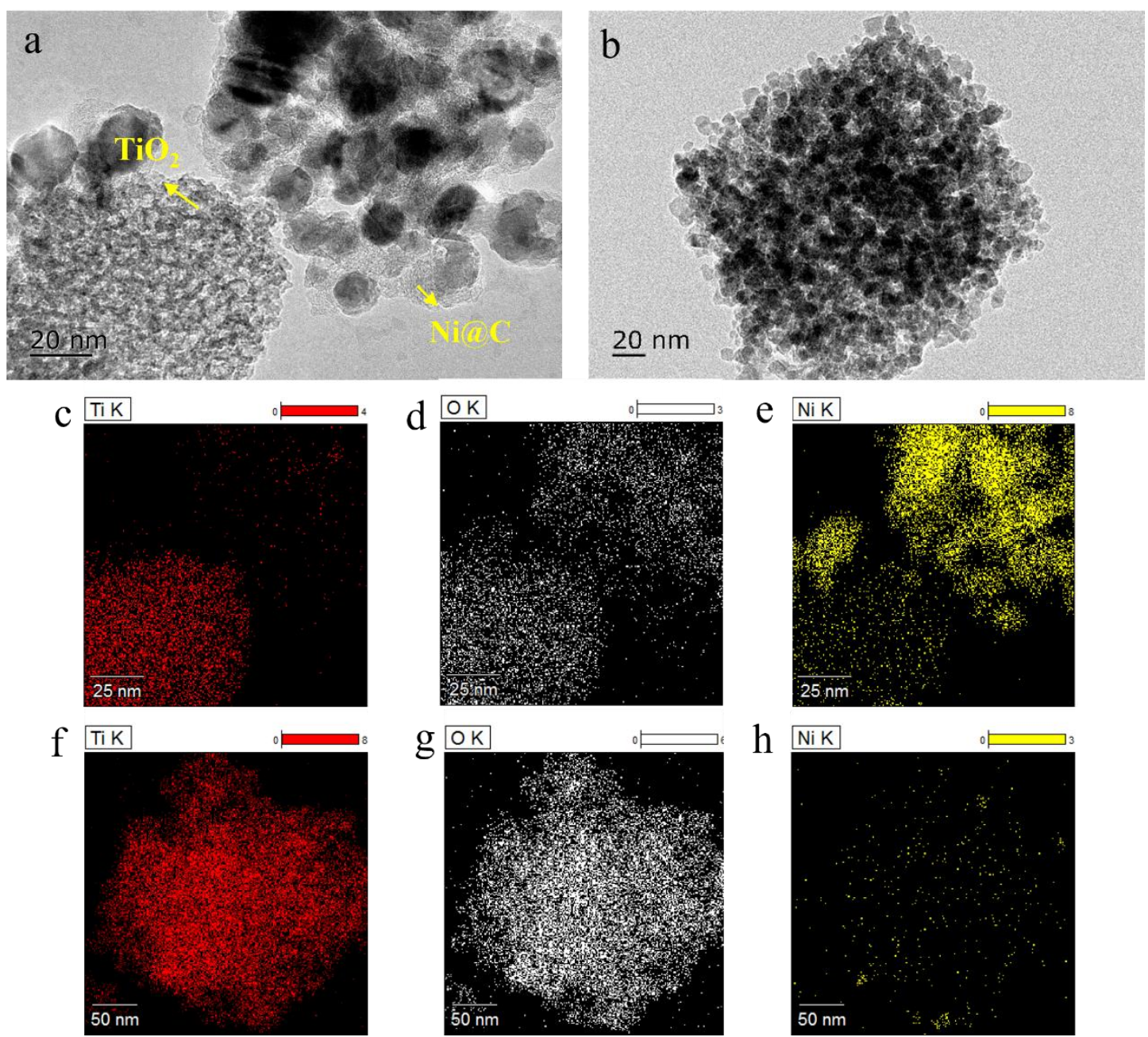

Figure 4. TEM image and MAP energy spectrum. a: TEM image of $\mathrm{Ni} @ \mathrm{C} / \mathrm{TiO}_{2}-5 \mathrm{~nm}$;

b: TEM image of $\mathrm{Ni} @ \mathrm{C} / \mathrm{TiO}_{2}-\mathrm{Z}$; c: MAP image of $\mathrm{Ni} @ \mathrm{C} / \mathrm{TiO}_{2}-5 \mathrm{~nm} \mathrm{Ti}$; d: MAP image of $\mathrm{Ni} @ \mathrm{C} / \mathrm{TiO}_{2}-5$ nm O; e: $\mathrm{MAP}$ image of $\mathrm{Ni} @ \mathrm{C} / \mathrm{TiO}_{2}-5 \mathrm{~nm} \mathrm{Ni}$; f: MAP image of $\mathrm{Ni} @ \mathrm{C} / \mathrm{TiO}_{2}-\mathrm{ZTi}$; g: MAP image of $\mathrm{Ni} @ \mathrm{C} / \mathrm{TiO}_{2}-\mathrm{Z} \mathrm{O}$; h: MAP image of

\section{$\mathrm{Ni} @ \mathrm{C} / \mathrm{TiO}_{2}-\mathrm{Z} \mathrm{Ni}$.}

To differentiate the catalytic activities, microstructures of the $\mathrm{Ni} @ \mathrm{C} / \mathrm{TiO}_{2}-5 \mathrm{~nm}$ and $\mathrm{Ni} @ \mathrm{C} / \mathrm{TiO}_{2}-\mathrm{Z}$ were studied by TEM. It can be seen from Figure 4 that $\mathrm{TiO}_{2}$ and $\mathrm{Ni} @ \mathrm{C}$ in $\mathrm{Ni} @ \mathrm{C} / \mathrm{TiO}_{2}-5 \mathrm{~nm}$ is not uniformly mixed, while $\mathrm{TiO}_{2}$ and $\mathrm{Ni} @ \mathrm{C}$ in $\mathrm{Ni} @ \mathrm{C} / \mathrm{TiO}_{2}-\mathrm{Z}$ prepared in situ are uniformly mixed. The distribution of $\mathrm{Ti}$ and $\mathrm{Ni}$ elements in MAP also provides evidence for the above conclusions. 

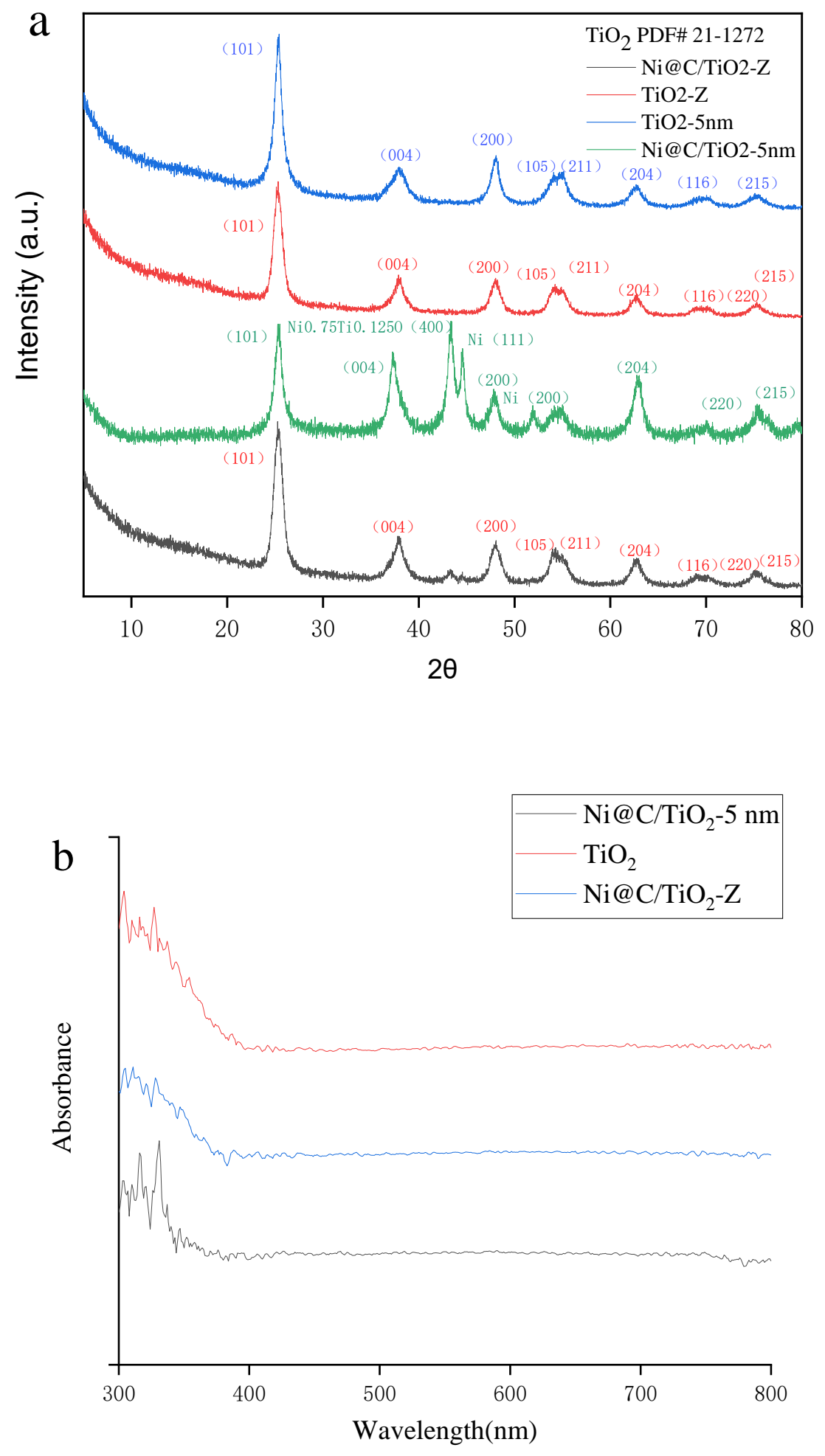

Figure 5. XRD and UV-Vis absorption spectra of the catalyst. a: XRD of catalyst; b: UV-Vis absorption spectra of the catalyst.

Figure 5 (a) is the XRD diffraction patterns of $\mathrm{TiO}_{2}-5 \mathrm{~nm}, \mathrm{TiO}_{2}-\mathrm{Z}, \mathrm{Ni} @ \mathrm{C} / \mathrm{TiO}_{2}-5$ $\mathrm{nm}$, and $\mathrm{Ni} @ \mathrm{C} / \mathrm{TiO}_{2}-\mathrm{Z}$. The lattice types of $\mathrm{TiO}_{2}$ in these catalysts are the same. The 
difference is that there are two larger $\mathrm{Ni}\left(\begin{array}{lll}1 & 1 & 1\end{array}\right)$ peaks at $43.3^{\circ}$ and $44.5^{\circ}$ in $\mathrm{Ni} @ \mathrm{C} / \mathrm{TiO}_{2}-5 \mathrm{~nm}$, while $\mathrm{Ni} @ \mathrm{C} / \mathrm{TiO}_{2}-\mathrm{Z}$ has only two small peaks here. It may be due to uneven dispersion of $\mathrm{Ni} @ \mathrm{C}$ in $\mathrm{Ni} @ \mathrm{C} / \mathrm{TiO}_{2}-5 \mathrm{~nm}$. In addition, the UV-Vis spectra of $\mathrm{TiO}_{2}-\mathrm{Z}, \mathrm{Ni} @ \mathrm{C} / \mathrm{TiO}_{2}-5 \mathrm{~nm}$ and $\mathrm{Ni} @ \mathrm{C} / \mathrm{TiO}_{2}-\mathrm{Z}$ were measured. From Figure 5(b) their absorption peak of the UV-Vis absorption spectrum were around $380 \mathrm{~nm}$. Therefore, according to the Kubelka-Munk formula, there is no significant difference in the forbidden band width among them.

\section{Conclusion}

Herein, $\mathrm{Ni@C/TiO} 2-\mathrm{Z}$ catalyst was prepared by in-situ hydrothermal synthesis, which has better catalytic effect than the commercially available $\mathrm{TiO}_{2}$ supported by $\mathrm{Ni} @ \mathrm{C}$. And $\mathrm{Ni} @ \mathrm{C}$ more evenly dispersed. $\mathrm{Ni} @ \mathrm{C} / \mathrm{TiO}_{2}-\mathrm{Z}$ can catalyze the oxidation of a variety of aromatic alcohols to produce aldehydes or acids, and the catalytic activity did not decrease after 4 cycles of experiments. Choosing different solvents could adjust the products, such as aromatic aldehydes or aromatic acids. This provides a theoretical basis for the industrial utilization of photocatalytic alcohol oxidation to produce aldehydes or acids in the future.

\section{Declaration of Competing Interest}

The authors declare that they have no known competing financial interests or personal relationships that could have appeared to influence the work reported in this work.

\section{Author Contributions}

J.G. L. and Q. Z. conceived and designed the experiments. Z.L.S. performed the experiments, analyzed the data and prepared the Supplementary Information. Z.L.S. wrote the original manuscript. J.G.L and Q. Z. corrected the paper. All authors discussed the results and commented on the manuscript.

\section{Acknowledgements}

This work was supported financially by the National Natural Science Foundation of China (51876209, 51976225).

\section{References}

[1] CLARIZIA L, APUZZO J, DI SOMMA I, et al. Selective photo-oxidation of ethanol to acetaldehyde and acetic acid in water in presence of $\mathrm{TiO}_{2}$ and cupric ions under $\mathrm{UV}$-simulated solar radiation [J]. Chem. Eng. J., 2019, 361: 1524-34.

[2] XIAO X, ZHENG C, LU M, et al. Deficient $\mathrm{Bi}_{24} \mathrm{O}_{31} \mathrm{Br}_{10}$ as a highly efficient photocatalyst for selective oxidation of benzyl alcohol into benzaldehyde under blue LED irradiation [J]. Appl. Catal. B: Environ., 2018, 228: 142-51.

[3] GOKSU H, BURHAN H, MUSTAFOV S D, et al. Oxidation of Benzyl Alcohol Compounds in the Presence of Carbon Hybrid Supported Platinum Nanoparticles ( $\mathrm{Pt} @ \mathrm{CHs}$ ) in Oxygen Atmosphere [J]. Sci. Rep., 2020, 10(1): 5439.

[4] HU Y L, FANG D. Efficient and convenient oxidation of alcohols to aldehydes and ketones with molecular oxygen mediated by $\operatorname{In}\left(\mathrm{NO}_{3}\right)_{3}$ in ionic liquid $\left[\mathrm{C}_{12} \mathrm{mim}\right]\left[\mathrm{FeBr}_{4}\right]$ [J]. Comptes. Rendus. Chimie., 2015, 18(6): 614-8.

[5] STAHL S S. Palladium oxidase catalysis: selective oxidation of organic chemicals by direct dioxygen-coupled turnover [J]. Angew. Chem. Int. Ed., 2004, 43(26): 3400-20. 
[6] RIEMER D, MANDAVIYA B, SCHILLING W, et al. $\mathrm{CO}_{2}$-Catalyzed Oxidation of Benzylic and Allylic Alcohols with DMSO [J]. ACS Catal., 2018, 8(4): 3030-4.

[7] BAIKER T M A A. Oxidation of Alcohols with Molecular Oxygen on Solid Catalysts [J]. Chem. Rev., 2004, 104(6): 3037-58.

[8] DAVIS S E, IDE M S, DAVIS R J. Selective oxidation of alcohols and aldehydes over supported metal nanoparticles [J]. Green Chem., 2013, 15(1): 17-45.

[9] CHAN-THAW C E, VILLA A, KATEKOMOL P, et al. Covalent triazine framework as catalytic support for liquid phase reaction [J]. Nano Lett., 2010, 10(2): 537-41.

[10] CHAN-THAW C E, VILLA A, VEITH G M, et al. Influence of periodic nitrogen functionality on the selective oxidation of alcohols [J]. Chem. Asian J., 2012, 7(2): 387-93.

[11] YASU-EDA T, SE-IKE R, IKENAGA N-O, et al. Palladium-loaded oxidized diamond catalysis for the selective oxidation of alcohols [J]. J. Molecular Catal. A: Chem., 2009, 306(1-2): $136-42$.

[12] DIMITRATOS N, LOPEZ-SANCHEZ J A, HUTCHINGS G J. Selective liquid phase oxidation with supported metal nanoparticles [J]. Chem Sci., 2012, 3(1): 20-44.

[13] LI G, ENACHE D I, EDWARDS J, et al. Solvent-free oxidation of benzyl alcohol with oxygen using zeolite-supported $\mathrm{Au}$ and $\mathrm{Au}-\mathrm{Pd}$ catalysts [J]. Catalysis Letters, 2006, 110(1-2): 7 13.

[14] ENACHE D I, EDWARDS J K, LANDON P, et al. Solvent-free oxidation of primary alcohols to aldehydes using $\mathrm{Au}-\mathrm{Pd} / \mathrm{TiO}_{2}$ catalysts [J]. Science, 2006, 311(5759): 362-5.

[15] A. FUJISHIMA K H. Electrochemical Photolysis of Water at a Semiconductor Electrode [J]. Nature 1972, 238: 37-8.

[16] DONG H, ZENG G, TANG L, et al. An overview on limitations of $\mathrm{TiO}_{2}$-based particles for photocatalytic degradation of organic pollutants and the corresponding countermeasures [J]. Water Res, 2015, 79: 128-46.

[17] NAKATA K, FUJISHIMA A. $\mathrm{TiO}_{2}$ photocatalysis: Design and applications [J]. Journal of Photochemistry and Photobiology C: Photochemistry Reviews, 2012, 13(3): 169-89.

[18] KOH M J, KHAN R K, TORKER S, et al. High-value alcohols and higher-oxidation-state compounds by catalytic Z-selective cross-metathesis [J]. Nature, 2015, 517(7533): 181-6.

[19] MASARWA A, DIDIER D, ZABRODSKI T, et al. Merging allylic carbon-hydrogen and selective carbon-carbon bond activation [J]. Nature, 2014, 505(7482): 199-203.

[20] SHIRAISHI Y, HIRAI T. Selective organic transformations on titanium oxide-based photocatalysts [J]. Journal of Photochemistry and Photobiology C: Photochemistry Reviews, 2008, 9(4): 157-70.

[21] KEGEL J, POVEY I M, PEMBLE M E. Zinc oxide for solar water splitting: A brief review of the material's challenges and associated opportunities [J]. Nano Energy, 2018, 54: 409-28.

[22] MA J, REN J, JIA Y, et al. High efficiency bi-harvesting light/vibration energy using piezoelectric zinc oxide nanorods for dye decomposition [J]. Nano Energy, 2019, 62: 376-83.

[23] LIU Y, JIAO Y, ZHANG Z, et al. Hierarchical $\mathrm{SnO}(2)$ nanostructures made of intermingled ultrathin nanosheets for environmental remediation, smart gas sensor, and supercapacitor applications [J]. ACS Appl. Mater. Interf., 2014, 6(3): 2174-84.

[24] KANSAL S K, SINGH M, SUD D. Studies on photodegradation of two commercial dyes in aqueous phase using different photocatalysts [J]. J. Hazard. Mater., 2007, 141(3): 581-90.

[25] LI Q, GUO B, YU J, et al. Highly efficient visible-light-driven photocatalytic hydrogen production of CdS-cluster-decorated graphene nanosheets [J]. J. Am. Chem. Soc., 2011, 133(28): 10878-84.

[26] YAN H, YANG J, MA G, et al. Visible-light-driven hydrogen production with extremely high quantum efficiency on Pt-PdS/CdS photocatalyst [J]. J. Catal., 2009, 266(2): 165-8.

[27] LI Q, LI X, WAGEH S, et al. CdS/Graphene Nanocomposite Photocatalysts [J]. Adv. Energy Mater., 2015, 5(14).

[28] R. ASAHI T M, T. OHWAKI, K. AOKI, AND Y. TAGA. Visible-Light Photocatalysis in Nitrogen-Doped Titanium Oxides [J]. SCIENCE, 2001, 293(5528): 269-71.

[29] AFFILIATIONS X C L Y Y S S M A I. Increasing Solar Absorption for Photocatalysis with Black Hydrogenated Titanium Dioxide Nanocrystals [J]. SCIENCE, 2011, 331(6018): 746-50.

[30] KARIMI-MALEH H, KUMAR B G, RAJENDRAN S, et al. Tuning of metal oxides photocatalytic performance using Ag nanoparticles integration [J]. J. Molecular Liq., 2020, 314.

[31] XU F, MENG K, CHENG B, et al. Unique S-scheme heterojunctions in self-assembled 
$\mathrm{TiO} 2 / \mathrm{CsPbBr} 3$ hybrids for $\mathrm{CO} 2$ photoreduction [J]. Nat. Commun., 2020, 11(1): 4613.

[32] DENG X, CHEN Y, WEN J, et al. Polyaniline- $\mathrm{TiO}_{2}$ composite photocatalysts for light-driven hexavalent chromium ions reduction [J]. Science Bulletin, 2020, 65(2): 105-12.

[33] GUO Q, ZHOU C, MA Z, et al. Fundamentals of $\mathrm{TiO}_{2}$ Photocatalysis: Concepts, Mechanisms, and Challenges [J]. Adv. Mater., 2019, 31(50): e1901997.

[34] ZHAO Z, REISCHAUER S, PIEBER B, et al. Carbon $\operatorname{dot} / \mathrm{TiO}_{2}$ nanocomposites as photocatalysts for metallaphotocatalytic carbon-heteroatom cross-couplings [J]. Green Chem., 2021, 23(12): 4524-30.

[35] XU L, BAI X, GUO L, et al. Facial fabrication of carbon quantum dots (CDs)-modified N$\mathrm{TiO}_{2}$-X nanocomposite for the efficient photoreduction of $\mathrm{Cr}(\mathrm{VI})$ under visible light $[\mathrm{J}]$. Chem. Eng. J., 2019, 357: 473-86.

[36] WANG B, LANTERNA A E, SCAIANO J C. Mechanistic Insights on the Semihydrogenation of Alkynes over Different Nanostructured Photocatalysts [J]. ACS Catal., 2021, 11(7): 4230-8.

[37] YURDAKAL S, ÇETINKAYA S, ÖZCAN L, et al. Partial photoelectrocatalytic oxidation of 3-pyridinemethanol by Pt, Au and $\mathrm{Pd}$ loaded $\mathrm{TiO}_{2}$ nanotubes on Ti plate [J]. Catal. Today, 2021, 380: 248-58.

[38] KASHYAP T, BISWAS S, AHMED S, et al. Plasmon activation versus plasmon quenching on the overall photocatalytic performance of $\mathrm{Ag} / \mathrm{Au}$ bimetal decorated $\mathrm{g}-\mathrm{C}_{3} \mathrm{~N}_{4}$ nanosheets under selective photoexcitation: A mechanistic understanding with experiment and theory [J]. Appl. Catal. B: Environ., 2021, 298.

[39] LIU Y, LI Y, PENG F, et al. 2H- and 1T- mixed phase few-layer $\mathrm{MoS}_{2}$ as a superior to Pt cocatalyst coated on $\mathrm{TiO}_{2}$ nanorod arrays for photocatalytic hydrogen evolution [J]. Applied Catalysis B: Environmental, 2019, 241: 236-45.

[40] MENG A, ZHANG L, CHENG B, et al. TiO $2-\mathrm{MnO}$ x-Pt Hybrid Multiheterojunction Film Photocatalyst with Enhanced Photocatalytic $\mathrm{CO}_{2}$-Reduction Activity [J]. ACS Appl. Mater. Interf., 2019, 11(6): 5581-9.

[41] LIU Q, WANG H, XIN H, et al. Selective Cellulose Hydrogenolysis to Ethanol Using Ni@C Combined with Phosphoric Acid Catalysts [J]. ChemSusChem, 2019, 12(17): 3977-87. 